\title{
Evaluation of perinatal factors in neonatal sepsis at tertiary centre
}

\author{
Raju Kumar1*, Anita Kumari², Anjili Kumari², Neelam Verma $^{3}$
}

\begin{abstract}
${ }^{1}$ Department of Pediatrics, ${ }^{2}$ Department of Obstetrics and Gynecology, IGIMS, Patna, Bihar, India
\end{abstract}
${ }^{3}$ Department of Pediatrics, PMCH, Patna, Bihar, India

Received: 21 August 2017

Revised: 01 September 2017

Accepted: 16 September 2017

\section{*Correspondence:}

Dr. Raju Kumar,

E-mail: pmch.raju@gmail.com

Copyright: ( $)$ the author(s), publisher and licensee Medip Academy. This is an open-access article distributed under the terms of the Creative Commons Attribution Non-Commercial License, which permits unrestricted non-commercial use, distribution, and reproduction in any medium, provided the original work is properly cited.

\begin{abstract}
Background: Neonatal mortality in India continues to remain a major health problem. Neonatal infections are one of the major contributor to neonatal mortality causing approximately one-quarter of the deaths. The signs of neonatal sepsis may be non-specific and easily missed, especially in the early stages. A high index of suspicion and identification of both maternal and neonatal risk factors is an important for early identification and prompt treatment. Methods: This is prospective study done at Patna medical college and hospital Patna from February 2014 to January 2015 in department of paediatrics. All inborn and out born neonates who had clinical signs of sepsis were included in the study.

Results: During the 1-year study period, there were a total of 910 admissions in the NICU, out of which 175 were admitted due to neonatal septicaemia. Incidence of neonatal septicaemia was approximately $20 \%$. Mean age at

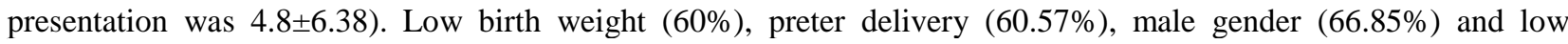
APGAR score at 1 minute were common foetal risk factor and prolonged labour $(41.14 \%)$ and multiple vaginal examination (36.57\%), PROM in $28 \%$, MSL $(25.71 \%)$ were common maternal risk factors. Present study documented a culture positivity rate of $42.28 \%$. E. coli $(37.83 \%)$ was the most common isolated organism in early as well as LOS. Staphylococcus aureus (20.27\%) was the most common isolated Gram-positive bacterium. Mortality rate was $45.14 \%$. Mortality was more in preterm babies $(57.54 \%)$ which was statically significant $\mathrm{p}$ value $<0.001$.

Conclusions: Neonatal septicemia is common and serious condition with high mortality rate. Since the condition starts with vague clinical signs, one has to keep very high index of suspicion to diagnose neonatal sepsis. Diagnosis and treatment at the early stage is very important for favorable outcome. Proper antenatal care, and institutional delivery may decrease neonatal sepsis.
\end{abstract}

Keywords: Antenatal care, Neonatal septicemia, Neonatal sepsis, Perinatal factors

\section{INTRODUCTION}

Neonatal mortality in India continues to remain a major health problem. According to the 2010 census, the neonatal mortality rate in our country was 33/1000 live births. $^{1}$ Neonatal infections are one of the major contributor to neonatal mortality causing approximately one-quarter of the deaths. ${ }^{2}$ The signs of neonatal sepsis may be non-specific and easily missed, especially in the early stages. A high index of suspicion and identification of both maternal and neonatal risk factors is an important factor for early identification and prompt treatment. Of necessity, many more babies are evaluated and treated for sepsis than those who actually have the condition. ${ }^{3}$ Etiological causes also vary with a wide variety of aerobic and anaerobic bacteria causing neonatal sepsis. 
Various risk factors for neonatal sepsis, such as prolonged rupture of membrane (PROM), prematurity, low birth weight (LBW), male sex, operative vaginal or instrumental deliveries, multiple vaginal examination, meconium stained liquor and birth asphyxia have been identified. But the relative importance of these risk factors in the etiology of neonatal septicaemia varies in different study populations. ${ }^{4-6}$ Studies from the Indian subcontinent have demonstrated different causative organisms as compared to Western studies. ${ }^{6-8}$

There are large number of studies across the India to establish cause of neonatal infections. However, there was a large number of patients with neonatal sepsis were being admitted to the neonatal intensive care unit (NICU) of our institute.

There was need to know the aetiology and risk factor of neonatal sepsis. Therefore, this study was done to determine the bacterial profile patterns of aerobic isolates from blood cultures of neonates at our tertiary care hospital and also to identify the risk factors for earlyonset sepsis (EOS) and late onset sepsis (LOS) prevalent in our study population.

EOS was defined as the presence of positive blood culture in neonates $<72 \mathrm{~h}$ of age who had clinical signs or risk factors for sepsis. Late-onset sepsis (LOS) was defined as a positive blood culture in neonates more than $72 \mathrm{~h}$ of age who had risk factors or clinical signs of sepsis. ${ }^{9,10}$

\section{METHODS}

This is prospective study done at Patna medical college and hospital Patna from February 2014 to January 2015 in Department of Pediatrics. The NICU at our medical college and hospital caters to babies born at this hospital as well as out born from the surrounding areas with a total capacity of 20 intensive care beds. All inborn and out born neonates who had clinical signs of sepsis were included in the study.

Detailed antenatal history regarding gestational age, maternal pyrexia, prolonged labour, PROM for more than $24 \mathrm{~h}$, foul smelling or meconium stained liquor (MSL), or frequent (>3) unclean vaginal examinations was taken. Regarding natal history, having severe prematurity, or birth asphyxia necessitating active resuscitation, birth following instrumental delivery, endotracheal intubation was noted. All neonates were categorized into early onset ( $<72$ hours) or late onset ( $>72$ hours) sepsis based on the day of presentation.

All neonates admitted with maternal risk factors for sepsis or clinical signs of sepsis including newborns with lethargy, refusal to feed, abdominal distension, respiratory distress, temperature instability, pathological jaundice, convulsions, autonomic disturbances, and bleeding manifestations with constitutional symptoms undergo a septic screen and blood culture. Septic screen includes blood investigation like of total leucocyte counts, absolute neutrophil count, the ratio of immature neutrophils to total neutrophils, and a qualitative creactive protein (CRP) and this was sent to pathology department of our institute.

Culture sensitivity of blood was sent to microbiology department of institute. The septic screen was regarded as positive when two out of four parameters were positive.

All neonates were treated with injectable antibiotics without waiting culture report according to antibiotic guidelines in NICU. Outcome of neonates was noted.

\section{Statistical analysis}

Statistical significance was set as $\mathrm{P}$ value of less than 0.5 and P less 0.0001. Data was analyzed by Chi square test. Statistical analysis was performed using Epi Info Version 6.00 .

\section{RESULTS}

During the 1-year study period, there were a total of 910 admissions in the NICU, out of which 175 were admitted due to neonatal septicaemia. Out of 175 neonates, 164 were born outside $\mathrm{PMCH}$ while 11 were babies of booked mother. Incidence of neonatal septicaemia was approximately $20 \%$ (Table 1).

Table 1: Incidence of neonatal sepsis.

\begin{tabular}{lllll} 
Total & $\begin{array}{l}\text { Total } \\
\text { admission }\end{array}$ & $\begin{array}{l}\text { Delivered } \\
\text { at }\end{array}$ & $\begin{array}{l}\text { Delivered } \\
\text { outside }\end{array}$ & Incidence \\
cases & PMCH & PMCH & \\
910 & 175 & 11 & 164 & $19.23 \%$ \\
\hline
\end{tabular}

Mean age at presentation was $4.8 \pm 6.38 \mathrm{~h}$. An analysis of the perinatal risk factors showed that except postnatal age at the time of presentation the differences between the EOS and LOS groups were not statistically significant.

Low birth weight (60\%), preterm delivery (60.57\%), male gender $(66.85 \%)$ and low APGAR score at 1 minute were common risk factor for neonatal sepsis. Maternal risk factor and association of neonatal infection with mode of delivery was also analysed (Table 2).

Among 175, 74 neonates were culture positive and in these culture positive neonates, E. coli was the most common isolated organism in early as well as LOS. Staphylococcus aureus was the most common isolated Gram-positive bacterium.

The third most frequent organism was klebsiella. The other commonly isolated organisms were pseudomonas, coagulase-negative staphylococci, and Enterococci (Table $3)$. 
Table 2: Comparison of perinatal factor in early onset and late onset neonatal sepsis.

\begin{tabular}{|c|c|c|c|c|}
\hline Perinatal factor & Total $(n=175)$ & $\operatorname{EOS}(n=112)$ & LOS $(n=63)$ & $P$ value \\
\hline \multicolumn{5}{|l|}{ Neonatal factor } \\
\hline Mean postnatal age & $4.86 \pm 6.38$ & $1.25 \pm 0.90$ & $11.67 \pm 8.54$ & $<0.001$ \\
\hline \multicolumn{5}{|l|}{ Birth weight } \\
\hline$<2.5 \mathrm{Kg}$ & $115(65.71 \%)$ & $85(75.89 \%)$ & $30(46.87 \%)$ & \multirow[t]{2}{*}{0.485} \\
\hline$>2.5 \mathrm{~K}$ & $60(34.28 \%)$ & $40(35.71 \%)$ & $20(34.37 \%)$ & \\
\hline Preterm deliver & $106(60.57 \%)$ & $64(57.14 \%)$ & $42(65.62 \%)$ & 0.365 \\
\hline \multicolumn{5}{|l|}{ Sex } \\
\hline Male & $117(66.85 \%)$ & $76(67.85 \%)$ & $41(64 \%)$ & \multirow[t]{2}{*}{0.581} \\
\hline Female & $58(33.14 \%)$ & $38(33.40 \%)$ & $20(34.37 \%)$ & \\
\hline APGRA at 1 minute $<7$ & $81(46.28 \%$ & $54(48.21 \%)$ & $27(42.18 \%)$ & 0.362 \\
\hline Respiratory distress & $56(32 \%)$ & $34(30.35 \%)$ & $22(34.37 \%)$ & 0.623 \\
\hline Endotrachial intubation & $27(15.42 \%)$ & $18(16.07 \%)$ & $9(14.06 \%)$ & 0.408 \\
\hline Umbilical catheterization & $4(2.28 \%)$ & $4(2.28)$ & 0 & \\
\hline \multicolumn{5}{|l|}{ Maternal Factor } \\
\hline Prolonged labour & $72(41.14 \%)$ & $51(45.53 \%)$ & $21(32.81 \%)$ & 0.624 \\
\hline Multiple vaginal examination & $64(36.57 \%)$ & $46(41.07 \%)$ & $18(28.12 \%)$ & 0.241 \\
\hline PROM $>24$ hours & $49(28 \%)$ & $35(31.25 \%)$ & $14(21.87 \%)$ & 0.652 \\
\hline Meconium stained liquor & $45(25.71 \%)$ & $34(30.35 \%)$ & $11(17.18 \%)$ & 0.481 \\
\hline Maternal fever & $26(14.85 \%)$ & $17(15.17 \%)$ & $9(14.06 \%)$ & 0.325 \\
\hline \multicolumn{5}{|l|}{ Mode of delivery } \\
\hline NVD & $101(58 \%)$ & $77(68.75 \%)$ & $24(37.5 \%)$ & 0.381 \\
\hline LSCS & $46(32 \%)$ & $30(26.78 \%)$ & $26(40.62 \%)$ & 0.643 \\
\hline Operative VD & $28(16 \%)$ & $21(18.75 \%)$ & $7(10.93 \%)$ & 0.261 \\
\hline
\end{tabular}

Table 3: Bacteriological profile.

\begin{tabular}{|lll|}
\hline Organism & Number & Percentage \\
\hline Gram negative & 47 & 63.51 \\
\hline E. coli & 28 & 37.83 \\
\hline Klebsiella & 10 & 13.51 \\
\hline Pseudomonas & 7 & 9.45 \\
\hline Proteus & 2 & 2.70 \\
\hline Gram positive & 27 & 36.48 \\
\hline Staph aureus & 15 & 20.27 \\
\hline CONS & 6 & 8.10 \\
\hline Enterococcus & 4 & 5.40 \\
\hline GBS & 2 & 2.32 \\
\hline Total & 74 & 100 \\
\hline
\end{tabular}

Table 4: Neonatal mortality in neonatal septicaemia.

\begin{tabular}{|c|c|c|c|c|}
\hline Category & Number & $\begin{array}{l}\text { No. of } \\
\text { death }\end{array}$ & & $\begin{array}{l}\mathbf{P} \\
\text { value }\end{array}$ \\
\hline \multicolumn{5}{|c|}{ Gestational age } \\
\hline Preterm & 106 & 61 & 57.54 & \multirow[t]{2}{*}{0.001} \\
\hline Term & 69 & 18 & 26.08 & \\
\hline \multicolumn{5}{|c|}{ Neonatal age } \\
\hline EOS & 112 & 47 & 41.96 & \multirow[t]{2}{*}{0.5} \\
\hline LOS & 64 & 26 & 40.62 & \\
\hline
\end{tabular}

Mortality rate was $45.14 \%$. mortality was more in preterm babies $(57.54 \%)$ which was statically significant that of in EOS and LOS was almost equal (Table 4).

\section{DISCUSSION}

Present study documented NICU admission rate of approximately $20 \%$. This was higher to that reported in previous studies done in India and Mexico. ${ }^{11,12}$ The higher rate of sepsis is due to illiteracy, low socioeconomic condition and due to poor antenatal care. In our study there was male predominance almost double to female because of sex specific custom practiced in the society, higher proportion of males were brought to the hospital and the locus of the gene for synthesis of immunoglobulins lies at X-chromosome.

We looked at the risk factors for neonatal sepsis in this study. Previous studies have shown an association between neonatal sepsis and factors such as prematurity, birth asphyxia, LBW, PROM, MSL, multiple vaginal examinations, chorioamnionitis, and urinary tract infections. ${ }^{7,13}$ In a recent study by Sharma et al., the main risk factors for neonatal sepsis were PROM and maternal exposure to antibiotics. ${ }^{6}$ In this study prolonged labour $(41.14 \%)$ and multiple vaginal examination (36.57\%), PROM in $28 \%$, MSL (25.71\%) were common risk factor. But this is not statistically significant, small sample size may be the reason. However, it is significant that the majority of neonates with sepsis in present study were preterm $(60.57 \%)$, and the birth weight less than $2.5 \mathrm{~kg}$ $(65.17 \%)$. This underlines the importance of the extra care that these infants need to prevent sepsis and sepsisrelated mortality and morbidity. 
Present study documented a culture positivity rate of $42.28 \%$. However, other studies have documented culture positivity rate of $26.6-46.2 \% .^{8,14}$ A high rate of culture positives may be due to the fact that screening for sepsis was done in all high-risk neonates as well as those with clinical features suggestive of sepsis. It has been documented that up to $26 \%$ cases of neonatal sepsis may be caused by anaerobes. ${ }^{15}$ In developing countries, pathogens isolated are different from those seen in developed nations. In present study, E. coli species were the most common isolated organisms in both early and LOS. This is similar to the findings reported in earlier studies and those reported in the National Neonatal Perinatal Database. ${ }^{11,16}$ In contrast, a study from Sikkim found Pseudomonas and Enterobacter species to be the predominant pathogens among Gram-negative organisms. ${ }^{17}$

Among the Gram-positive organisms, S. aureus was the most common isolated organism. Group B streptococcus, which is common in the west, is infrequent in Indiaand was isolated in 2 cases at our center. ${ }^{18,19}$ It is difficult to comment on the clinical significance of low virulence isolates such as coagulase-negative staphylococcus enterococci, and non-fermenting Gram-negative bacilli. However, in the clinical setting of sepsis, especially in small preterm neonates, it would not be wise to dismiss these isolates as contaminants. Babies with such isolates were treated for sepsis according to protocol, and we have reported these isolates in present study.

Mortality rate was higher $(45.14 \%)$ in present study as compare to other study due to delayed admission by the parents, poor compliance by attendants in procuring high cost antibiotics and less awareness and health education among health workers leading to delayed recognition of neonatal illness. mortality was more in preterm babies $(57.54 \%)$ which was statically significant (Table 4$)$.

\section{CONCLUSION}

Neonatal septicemia is common and serious condition with high mortality rate. Since the codition starts with vague clinical signs, one has to keep very high index of suspicion to diagnose neonatal sepsis. Diagnosis and treatment at the early stage is very important for favorable outcome. It is important to do proper antenatal care, avoid unhygienic delivery practices and home delivery by untrained dais. Institutional delivery should be encouraged.

\section{ACKNOWLEDGMENTS}

Authors would like to thank Mr. Chandan for their hard work and technical support during the study.

Funding: No funding sources

Conflict of interest: None declared

Ethical approval: Not required

\section{REFERENCES}

1. Estimates of mortality indicators-census of India. Available at http://www.censusindia.gov.in/vital statistics/srs/chap_4_- _2010.pdf. [Last accessed on 2015 Aug 15].

2. Million Death Study Collaborators, Bassani DG, Kumar R, Awasthi S, Morris SK, Paul VK, et al. Causes of neonatal and child mortality in India: A nationally representative mortality survey. Lancet. 2010;376(9755):1853-60.

3. Kumhar GD, Ramachandran VG, Gupta P. Bacteriological analysis of blood culture isolates from neonates in a tertiary care hospital in India. J Health Popul Nutr. 2002;20(4):343-7.

4. Vinodkumar CS, Neelagund YF, Suneeta K, Sudha B, Kalappannavar NK, Basavarajappa KG. Perinatal risk factors and microbial profile of neonatal sepsis. $\mathbf{J}$ Obstet Gynecol India. 2008;58(1):32-40.

5. Thapa B, Thapa A, Aryal DR, Thapa K, Pun A, Khanal S, et al. Neonatal sepsis as a major cause of morbidity in a tertiary center in Kathmandu. JNMA. 2013;52:549-56.

6. Sharma D, Kumar C, Pandita A, Pratap OT, Dasi T, Murki S. Bacteriological profile and clinical predictors of ESBL neonatal sepsis. J Matern Fetal Neonatal Med. 2015:1-4.

7. Schuchat A, Zywicki SS, Dinsmoor MJ, Mercer B, Romaguera J, O'Sullivan MJ, et al. Risk factors and opportunities for prevention of early-onset neonatal sepsis: A multicenter case-control study. Pediatrics. 2000;105:21-6.

8. Muley VA, Ghadage DP, Bhore AV. Bacteriological profile of neonatal septicemia in a tertiary Care Hospital from Western India. J Glob Infect Dis. 2015;7:75-7.

9. Singh M, editor. Neonatal septicemia. Care of the Newborn. $7^{\text {th }}$ ed. Philadelphia, PA: Sagar Publication;2009:223-9.

10. Ferrieri P, Wallen LD. Neonatal bacterial sepsis. In: Gleason CA, Deveskar SU, editors. Avery's Diseases of the Newborn. $9^{\text {th }}$ ed. Philadelphia, PA: Saunders, Elsevier; 2011:538-50

11. Jyothi P, Basavaraj MC, Basavaraj PV. Bacteriological profile of neonatal septicemia and antibiotic susceptibility pattern of the isolates. J Nat Sci Biol Med. 2013;4:306-9.

12. Leal YA, Álvarez-Nemegyei J, Velázquez JR, Rosado-Quiab U, Diego-Rodríguez N, Paz-Baeza E, et al. Risk factors and prognosis for neonatal sepsis in southeastern Mexico: Analysis of a four-year historic cohort follow-up. BMC Pregnancy Childbirth. 2012;12:48.

13. Kuruvilla KA, Pillai S, Jesudason M, Jana AK. Bacterial profile of sepsis in a neonatal unit in South India. Indian Pediatr. 1998;35(9):851-8.

14. Desai KJ, Malek SS, Parikh A. Neonatal. Septicemia: Bacterial isolates and their antibiotic susceptibility patterns. Gujarat Med J. 2011;66(1):13-5. 
15. Chow AW, Leake RD, Yamauchi T, Anthony BF, Guze LB. The significance of anaerobes in neonatal bacteremia: Analysis of 23 cases and review of the literature. Pediatrics. 1974;54(6):736-45.

16. National neonatal perinatal database-WHO Newborn CC. Available http://www.newbornwhocc.org/pdf/nnpd report_2002-03.PDF. [Last accessed on 2015 Aug $15]$.

17. Tsering DC, Chanchal L, Pal R, Kar S. Bacteriological profile of septicemia and the risk factors in neonates and infants in Sikkim. J Glob Infect Dis. 2011;3(1):42-5.
18. Mathur NB. Neonatal sepsis. Indian Pediatr. 1996;33:663-74.

19. Areen A, Mahajan K, Singh S. Impact of JSY scheme on incidence of low birth weight in a rural tertiary Care Hospital in Punjab. Indian J Matern Child Health. 2012;14(1):7.

Cite this article as: Kumar R, Kumari A, Kumari A, Verma N. Evaluation of perinatal factors in neonatal sepsis at tertiary centre. Int J Reprod Contracept Obstet Gynecol 2017;6:4981-5. 